\title{
Application of Alloyed Cast Iron to Increase the Durability of Products of the Mining and Metallurgical Industry
}

\author{
Dmitry Lubyanoi ${ }^{1 *}$, Evgeny Pudov $^{1}$, Evgeny Kuzin ${ }^{1}$, Olga Semenova ${ }^{1}$, and Radim Rybár ${ }^{2}$ \\ ${ }^{1}$ Branch of T.F. Gorbachev Kuzbass State Technical University in Prokopievsk, 653039, 19a \\ Nogradskaya str., Prokopievsk, Kemerovo region, Russian Federation \\ ${ }^{2}$ Technical University Košice, Faculty BERG, Letná 9, 04001 Košice, Slovakia
}

\begin{abstract}
The article shows the relevance of the use of alloyed cast iron in mining and metallurgical engineering. The use of cast iron alloyed with titanium and vanadium has not been sufficiently studied for the working bodies and friction units of mining machines, such as pumps, coal scoops, hydrocyclones, crushers and mills. They have the main abrasive type of wear. This work considers the influence of titanium and vanadium on the mechanical properties. The performance indicators of parts of mining machines and metallurgical products in contact with high-abrasive and high-temperature environments is also considered. The optimal content of titanium and vanadium in gray cast iron in the range of $0.05-0.1 \%$ is set. This provides the required strength properties of the components, while increasing their heat resistance. Bushings made of this cast iron have the required wear resistance and can improve the operational reliability of equipment in mining and metallurgical industries.
\end{abstract}

\section{Introduction}

The service life increase of machine parts of mining and metallurgical equipment is one of the most important problems of mechanical engineering. The low service life of products significantly reduces the economic efficiency of technologies and leads to their high metal content.

\section{Formulation of the problem}

The determination of the optimal content of alloying elements and a rational technology for metal melting is necessary for the optimal cast iron production technology with appropriate properties. It should be noted that vanadium can significantly reduce the content of manganese in heat-resistant cast iron. The task is to determine the concentration of manganese in cast iron with an optimal content of both titanium and vanadium. As it noted in [1], it remains relevant to increase the service life of critical parts in the coal and

\footnotetext{
*Corresponding author: Lubjanoy@yandex.ru
} 
metallurgical industries. These products and devices includes: pumps, armors of coalenrichment devices, coal scavengers, centrifuges, hydrocyclones, slag bowls, mills for metal ingots, coal - and ore-grinding mills, and pump bushings. The authors have proved that to produce the tools working in an abrasive environment is advised to produce from various types of white cast iron. It is also advisable to use complex alloys which have high wear resistance (5-10 times higher than structural steels) [1]. It is also possible to use optimally-alloyed gray cast iron, which have the maximum operational stability in the production of replaceable metallurgical equipment such as slags and molds (Fig.1) [2].

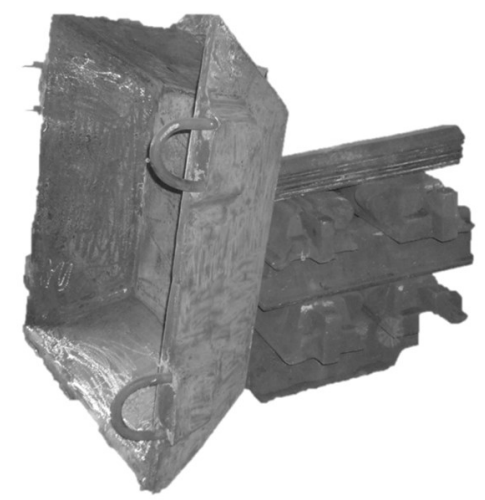

Fig. 1. Slag mills and molds for mining and metallurgical enterprises.

The properties of used white cast irons are known to be determined with the chemical composition of cast iron as well as manufacturing technology and the amount and size of carbides [1]. In [1], the influence on the mechanical properties and workability of white cast irons of carbon, chromium, molybdenum and phosphorus is studied. The effect of titanium and vanadium is not being studied enough. It is not enough both in studies of the properties of white cast irons and optimally doped gray heat-resistant cast irons [2-4].

It should be noted that, in addition to optimal alloying, the composition of the charge, the thermo-time melting modes and the after-furnace treatment of cast iron decisively influence on increasing the operational durability of products The effect of the composition of the charge is explained by the fact that pig iron contains an excess carbon content. The battle of cast iron heat-resistant castings differs in that during the manufacture of these castings. Cast iron was subjected to out-of-furnace refining with nitrogen or argon, while the melt is cleaned of excess carbon, gases and non-metallic inclusions. Scrap of heatresistant castings were made of cast iron in induction furnaces using thermal treatment of the melt. It also has a reduced content of gases and non-metallic inclusions which significantly improves the quality of products. These products are made of cast iron smelted in induction furnaces in the charge of which such scrap was used.

\section{Research result}

Under the conditions of Evraz ZSMK JSC, white wear-resistant cast iron [2] for wearresistant mining equipment (Fig. 2) of the icx17, ICX17N2, and ICX22N2MD2F grades are produced in a foundry equipped with induction furnaces ICT-10 $\mathrm{M}$ with acid lining using innovative technology with thermal melt treatment. 


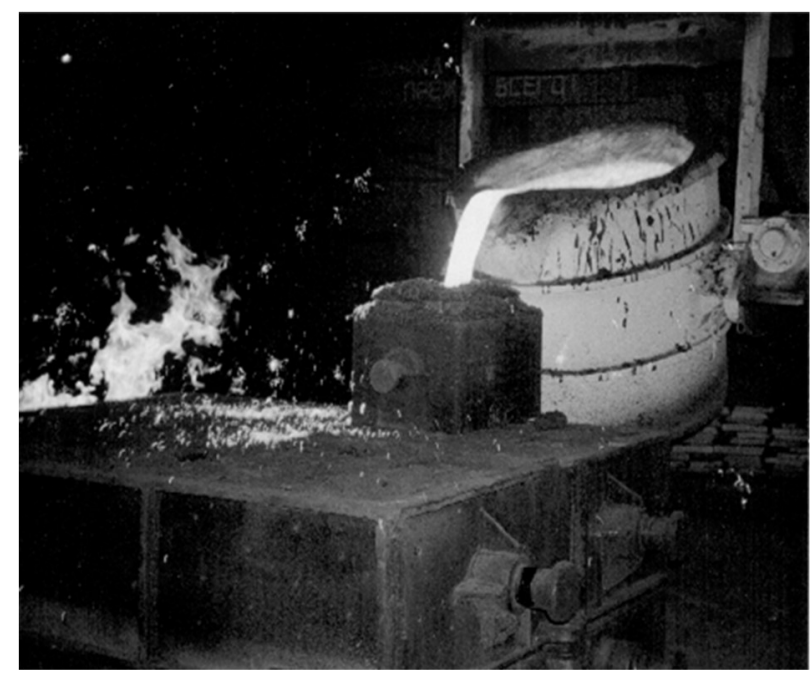

Fig. 2. Casting of alloy iron for the pumps mining industry.

White alloyed cast iron grades ICHH17, ICHH17N2 and ICHH22N2MD2F are melted in a hot crucible after complete draining of the previous cast iron melting. Nickel is an undesirable impurity in cast iron and ITS permissible content is not more than $0.1 \%$. When melting ICH17, you cannot use waste cast iron ICH17N2 and ICH22N2MD2F. When smelting iron grades ICHH17N2 and ICHH22N2MD2F in the charge you can use waste from your own production and iron ICHH17 production as well.

The components of the charge when smelting these grades are loaded into the furnace in the following order: 1) the bottom of hot crucible is loaded with a pre-assembled product of their own production of the same brands; 2) all the calculated amount of pig iron is loaded; 3) carbon ferrochrome FH800 is loaded; 4) steel scrap and then layer by layer ferrochrome and steel scrap in the ratio of $300 / 1000$ are loaded either. When welding iron ICHH22N2MD2F, granulated Nickel, ferrochrome and ferromolybdenum are loaded into the filling. In the first half of the melting process (before 3-4 $\mathrm{t}$ of liquid metal is deposited in the crucible), the next batch of charge is loaded into the furnace after the previous batch has fallen into the liquid metal. In the second half of the melting process the charge is loaded into the furnace for a well-warmed settled but not yet melted previous portion of the filling. The slag in the melting process is downloaded after the first half of the charge. It is melted at the end of the process before adjusting the chemical composition of the metal. When these cast irons are smelted for wear-resistant mining equipment, the operation of thermal-modern melt processing (TVO) is mandatory [2].

Basically the operation is in the process of heating up to certain temperatures and holding the melting. Homogenization occurs in it and the "near order" of the melting is achieved. It allows to increase the mechanical properties and performance of products made of wear-resistant cast iron for mining equipment. TVO temperatures are in the range of $1480-1540{ }^{\circ} \mathrm{C}$, exposure time is $10-15$ minutes. When smelting iron ICH17 provides heating to $1520-1540{ }^{\circ} \mathrm{C}$, iron ICH17N2 $1500-1520{ }^{\circ} \mathrm{C}$ and cast iron ICHH22N2MD2F $1480-1500{ }^{\circ} \mathrm{C}$. When smelting cast iron ICHH22N2MD2F metal overheating is above $1500{ }^{\circ} \mathrm{C}$.

Metal deoxidation in the furnace is performed with silicocalcium additive 10-15 minutes before release from the furnace. The metal is being poured into molds from a 2-ton ladle. Pouring metal into molds (Fig. 1) is performed with a slag cover of liquid cast iron in the casting bucket. The temperature of the metal before release from the furnace is within the range for $\mathrm{ICH} 171520-1540{ }^{\circ} \mathrm{C}$, for $\mathrm{ICH} 17 \mathrm{~N} 21500-1520{ }^{\circ} \mathrm{C}$; with and for $\mathrm{ICH}$ 
22N2MD2F $1400-1420{ }^{\circ} \mathrm{C}$. In the bucket before pouring, the temperature data should be in the range of ICH171460-1480 ${ }^{\circ} \mathrm{C}$, for ICH17N2 $1440-1460{ }^{\circ} \mathrm{C}$ and for ICH22N2MD2F $1360-1380{ }^{\circ} \mathrm{C}$. During the production of wear-resistant cast iron for mining equipment, the chemical composition of cast iron and the temperature during melting are being monitored. The content of carbon, manganese, silicon, chromium and Nickel is being controlled in cast iron $\mathrm{ICH} 17$ and $\mathrm{ICH} 17 \mathrm{H} 2$.

Under the conditions of EVRAZ ZSMK JSC, studies were conducted to assess the effect of titanium and vanadium doping of gray cast iron [3]. Studies have shown an increase in the tensile strength of cast iron in tension. These dependencies are described by the equations:

$$
\begin{aligned}
& \sigma=-3.71+291.7 \mathrm{~V} ; \\
& \sigma=-5.00+325.0 \mathrm{Ti} ;
\end{aligned}
$$

where $\sigma$ - tensile strength of cast iron, $\mathrm{kg} / \mathrm{mm}^{2} ; \mathrm{V}$, Ti-content of vanadium and titanium elements in cast iron, $\%$, respectively.

As the industrial tests have shown an increase in the strength properties of cast iron leads to a decrease in the erosion of products by the falling flow of molten metal. The alloying application under conditions of JSC EVRAZ ZSMK have increased the heat resistance of products by $7-12 \%[2,3]$. The test results showed that the high content of vanadium and titanium in cast iron leads to a decrease in the metal fluidity. It also leads to the porosity formation in the castings. Ferrophosphor $(\mathrm{P}=17 \%)$ was used in the ratio of 800 $\mathrm{kg}$ of alloy per 90 -ton bucket in order to increase the fluidity. Industrial tests have shown that shrinkage effects and micropores are practically absent in castings doped with phosphorus due to better filling of forms. This effect was observed when the phosphorus content in cast iron exceeds $0.21 \%$ [3].

The analysis of the main phases of cast iron: titanium carbide, phosphide eutectic and perlite matrix was performed using microstructure analysis [3]. Working out the optimal chemical composition it is necessary to try to obtain a favorable microstructure of cast iron for each specific case [3-10]. The naturally alloyed cast iron was found to have all the characteristics necessary to increase the service life of wear-resistant and heat-resistant products: high strength and wear resistance, and in the presence of phosphide eutectic, also good fluidity.

Naturally alloyed cast iron was used for casting the bushings of pumps for pumping liquid oxygen. Cast iron had the following chemical composition: carbon $3.65-3.825 \%$; silicon $1.6-1.9 \%$; manganese $0.45-0.60 \%$; sulfur $0.012-0.020 \%$; phosphorus $0.095-0.25 \%$; chromium $0.04-0.10 \%$; titanium $0.05-0.08 \%$ and vanadium $0.05-0.08 \%$. Pump bushings have been tested under aggressive production conditions. The tests showed that the wear resistance of the bushings was not inferior to the bushings obtained at other enterprises using powder metallurgy methods. Calculations of the cost of manufacturing these bushings were from 4 to 10 times lower than the cost of manufacturing bushings made of bronze or brass.

The efficiency of vanadium application in naturally alloyed cast iron to increase heat resistance was checked using statistical analysis methods. We have analyzed the coefficients in the regression equations for vanadium and manganese and have come to the conclusion that the alloying element vanadium affects almost three times more strongly on the operational stability of castings than manganese. The addition of expensive manganesecontaining ferroalloys can be reduced to the charge, while increasing the content of vanadium in the initial charge materials (initial blast cast iron or cast iron castings). The impact of vanadium and manganese on the stability of cast iron mills should be considered together, introducing the concept as the manganese equivalent of $\mathrm{Mn}_{\mathrm{ecv}}, \%$. 


$$
\mathrm{Mn}_{\mathrm{ecv}}=\mathrm{Mn}+3 \mathrm{~V} \text {. }
$$

Statistical processing allowed us to obtain regression equations of the influence of manganese equivalent on the service life of cast iron products. It as well allowed to mark its effect on the service life of wear-resistant products made of induction melting cast iron.

On the basis of the received dependences has been developed wear-resistant and heatresistant cast irons. They have found wide application in mining engineering and metallurgy. Products made from cast iron alloyed with vanadium and titanium have low production costs characteristics. These products are widely used in enterprises in Siberia and the Urals. In [11-15] other ways to improve the operational reliability, durability and wear resistance of products are also considered. It should be noted that the issue of increasing the wear resistance and operational stability of products must be approached comprehensively based on the results of this work. On the one hand, the properties of the materials of products should be taken into account. On the other hand, the properties of the materials of products the optimization of operating modes should be taken into account either.

\section{Conclusion}

The developed technologies have been revealed to allow high-quality mining equipment production from white alloyed cast iron with the use of innovative thermal processing of the melt. Manufactured products with the use of this technology have high wear resistance in abrasive environments and meet the customers' needs. The technologies are implemented on large induction furnaces of IHT-10m. Thus, cast iron is micro alloyed with titanium and vanadium. It significantly increases the strength properties of cast iron. Thereby it significantly increases the wear resistance of products working in conditions of abrasive wear and high temperatures. The optimal content of titanium and vanadium in gray cast iron in the range of $0.05-0.1 \%$. This provides the required strength properties of the components, while increasing their thermal stability. Bushings made of this cast iron have the required wear resistance. They allow increasing the operational reliability of equipment in mining and metallurgical industries. Vanadium is also an effective substitute for manganese. Alloying of metal with manganese is necessary in order to save manganesecontaining ferroalloys and to produce only the initial content of vanadium in cast iron which is only being taken into account.

It should be noted that the composition of the charge in addition to optimal alloying, thermal-modern melting modes and modes of non-furnace processing of cast iron have a determining influence on the increase in the operational stability of products. The effect of the charge composition is explained by the fact that the cast iron contains excess carbon content. The production of cast iron heat-resistant castings differs in that during the manufacture of these castings. The cast iron was subjected to extra-furnace refining with nitrogen or argon. The melt is cleared of excess carbon content, gases and non-metallic inclusions. The scrap of heat-resistant castings also has a reduced content of gases and nonmetallic inclusions, which were made from cast iron in induction furnaces with the use of thermally advanced melt processing. In turn it significantly improves the quality of products made from cast iron, which is smelted in induction electric furnaces in the charge of which such scrap was used.

Thus doping cast iron with chromium, vanadium, titanium and manganese has significantly improved the wear resistance of cast iron working in conditions of abrasive wear at mining and metallurgical enterprises of the country. Vanadium, titanium and manganese significantly increased the heat resistance and wear resistance of castings. These elements should be noted to be used for alloying cast iron products not separately but in a 
complex introducing the concept of manganese equivalent. The use of complex alloying can significantly reduce the consumption of manganese-containing ferroalloys. While it significantly reduce the cost of manufacturing products for mining and metallurgical production. These cast iron products are widely used in enterprises of the Urals and Siberia.

\section{References}

1. V. Studnicki, R. Dojka, M. Gromczyk, M. Kondracki, Archives of Foundry Engineering, 1, 117-123 (2016)

2. Yu. Samsonov, Foundry production, 4, 9-12 (2007)

3. D. Valeev, Metals, 10, 322 (2020)

4. S. O. Seidu, I.O. Ogunniyi, Materials Research, 16, 145 - 149 (2013)

5. E. Fras, M. Gorny, W. Kapturkiewicz, H.F. Lopez, Tsinghua Science \& Technology, 13, 177-189 (2008)

6. M. S. Ahamed, at al, International Journal of Engineering Research \&Technology, 3, 424-428 (2014)

7. E. Fras, Metals, 5, 256-288 (2015)

8. U. Klancnik, Journal of Thermal Analysis and Calorimetry, 127, 71-78 (2017)

9. I. Riposan, China Foundry, 8, 228-234 (2011)

10. L. C. Kumruoglu, Materials and Design, 30, 927-938 (2009)

11. G. Morales-Espejel, Evolution, 2, 25-30 (2010)

12. A. Mohamed, S. Sassi, M. Paurobally, Shock and Vibration, 2018, 1913289 (2018)

13. E. Kuzin, E3S Web of Conferences, 105, 03011 (2019)

14. M. Mamaeva, E. Kuzin, MATEC Web of Conferences, 297, 03006 (2019)

15. L. Saidi, J. Ben Ali, F. Fnaiech, ISA Transactions, 53, 1650-1660 (2014) 